\title{
Generating of spatial formations composed of carbon atoms as fullerenes and nanotubes type by applying of pulsed electrical discharges to the formation of graphite films on metallic surfaces
}

\author{
Laurentiu Marin ${ }^{1, *}$ \\ ${ }^{1}$ Institutul National de Cercetare Dezvoltare pentru Chimie si Petrochimie ICECHIM \\ Bucuresti.Bucuresti, Splaiul Independentei nr. 202, sector 6 Romania
}

\begin{abstract}
The present paper presents the results of experimental researchings concerning the technology for obtaining the graphite films on metallic surfaces by applying the method of electric pulsed discharges (DEI). It was established that the efficiency for the graphite film obtaining is according with the conecting mode for the workpiece subjected to treatment of electric pulsed discharges to the polarity of the electric pulse generator. Thin pellicles obtained after the electric pulsed discharges treatment, contain mostly carbon, but after of detailed and special analysis (termogravimetric analyses, electronic microscopy SEM and chemical analyses), it was found that different chemical forms of carbon other of graphite are generated. They are spatial formations made of carbon atoms the type of fullerenes and carbon nanotubes. This occurance explains the special functional properties of graphite films and that is to encapsulate small molecules such as $\mathrm{N}_{2}$ in the case of fullerenes, or organic molecules in case of nanotubes with single wall.
\end{abstract}

\section{Introduction}

The obtaining of graphite film at micro and nano scale, on the surfaces of metallic pieces made of different metals or alloys, determines its diffusion in a superficial layer on the metallic surface of the piece, and is accompanied by the formation of carbides with high hardness and also spatial formations made of carbon atoms the type of fullerenes and carbon nanotubes. [1-5]. Graphite film formation also determine the reducing of surface roughness.

In accordance with the experimental results obtained by the authors [4], the application of graphite films on the surfaces of components that make up the kinematic assemblies leads to reducing the coefficient of friction of about three times.

Graphite films obtained using pulsed electrical discharge technology with graphite cathode, maintain their good resistance for long time at temperatures of $300-400{ }^{\circ} \mathrm{C}$.

\footnotetext{
${ }^{*}$ Corresponding author: andree marr@yahoo.co.uk
} 
The procedure of surface treatment, which consists of depositing of graphite films by pulsed electrical discharges on the active surfaces of metal workpieces or subassemblies of some machine tools that are moving or there are in direct contact is a new and original method of surface processing which was not applied before. Specialized literature does not mention scientific interests or applications of the graphite film on metal workpiece. Most of technical and scientific communications which refer to surface treatments, have as subject these surface treatments which leading to improved the surface hardness or preventing the oxidation such as pack cementation, nitriding, carbonitriding,

This paper presents a part of the research activity of the doctoral thesis of the author Marin Laurentiu conducted under the coordination of mentors Prof Dr Hab Topala Pavel State University Alecu Russo Balti, Republic of Moldova and Prof Dr Hab Stoicev Petru Technical University of Moldova Chisinau

Applied researches and industrial experiments performed in the frame of the thesis have demonstrated that graphite film deposition is occur more efficient if the metal piece on that the deposition is done is connected to the positive pole - anode - and the graphite electrode who provide the graphite for deposit is connected to the negative pole - cathode - of the generator for electrical discharges in pulse. Under these circumstances the graphite films formed attains a thickness of about 7 microns $[2,5]$.

From above presented facts result that the submission of thin films of graphite on the surfaces of metallic pieces would solve a number of technical problems e.g. superficial wear resistance, reducing the coefficient of friction of the parts that make up the kinematic assemblies, avoidance of galling pieces.

\section{Experimental research methodology}

Experimental investigations have occurred under normal conditions of environment - 22 ${ }^{\circ} \mathrm{C}, 760 \mathrm{mmHg}$ and $65-70 \%$ relative humidity. The working environment was the atmosphere. Electrical pulsed discharges have been applied such that the flow of plasma that carries vaporized graphite to provide so-called cold spots to avoid unintentional melting of the metal.

As a tool electrode graphite rods were used with cylindrical in shape with sectional area of 5-7 $\mathrm{mm}^{2}$. The graphite rods used as tool electrode were the cathode. Target pieces on which the graphite were deposited were made of steel type OL45, OL 37, alloyed cast iron, bronze, brass. The target pieces have been connected to the positive pole of the pulse generator as anode.

In order to achieve graphite films by electrical pulsed discharges it was used an electric pulse generator [1]. It ensures the generation of electrical electrical pulsed discharges with the following parameters: the duration $10^{-6}-10^{-7} \mathrm{~s}$ which corresponds to the duration of ,cold spots electrode", energy released in the interstitium $\mathrm{W}_{\mathrm{S}}=0-4,8 \mathrm{~J}$, the accumulated energy in the capacitor $\mathrm{W}_{\mathrm{c}}=0-12 \mathrm{~J}$, applied voltage to charge the capacitor $\mathrm{U}_{\mathrm{c}}=0-250 \mathrm{~V}$, capacity of capacitors in the range $\mathrm{C}=100-600 \mu \mathrm{F}$ with a step of $100 \mu \mathrm{F}$. The generator provides high voltage electrical impulses $(\mathrm{U}=12-24 \mathrm{kV})$, which enables ignition of electric discharges at values of the interstitium of $\mathrm{S}=0,05-2,5 \mathrm{~mm}$. The frequency of electrical discharges was $\mathrm{f}=0-50 \mathrm{~Hz}$.

The morphology of surfaces on that were applied graphite film by the method of electric discharges in impulse was studied by scanning electron microscopy SEM and the chemical composition by the method EDX. 


\section{The results of experimental research}

\subsection{Choosing the shape and the material of the electrode}

During the process of applying graphite films by pulsed electrical discharge process, the shape of tool electrode is amended because graphite is consumed, which leads to the changing of operating parameters. In this way a set of operating parameters that ensure a predictable and controllable wear of electrode tool is required. In this purpose four values for capacitors $0,5 \mathrm{~J} ; 1 \mathrm{~J} ; 1,5 \mathrm{~J} ; 2 \mathrm{~J}$. have been set.

Tool electrodes with cylindrical, hemisphere and cone shape of the active area were used. This was done to identify the influence of active surface geometry of tool electrode on its depreciation. Figure 1 shows the dependence between the electrode tool wear of made of pyrolytic graphite, with active zone having a hemisfere shape and the accumulated on the capacitor. As can be seen in all cases the dependence electrode wear of is directly proportional to the accumulated energy from the capacitor.

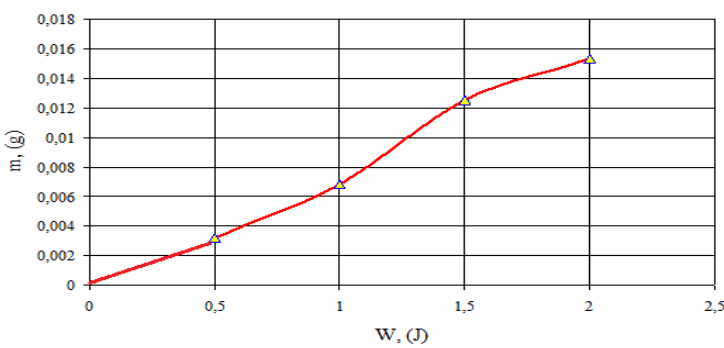

Fig. 1. The variation tool electrode wear depending on the accumulated energy in the capacitor. The active zone of electrode tool has the shape of a hemisphere

Figure 2 shows the dependence between the electrode tool made of pyrolytic graphite, with active zone having a sharp cone shape and the accumulated on the capacitor. As in the previous case the dependence electrode wear of is directly proportional to the accumulated energy from the capacitor. But when the shape of the active electrode tool is sharp, the slope of dependency graph wear of / energy is more pronounced which shows that the electrode consumption is faster through a sharp tip. This, leads to in default to the conclusion that the process for submitting graphite films over metallic surfaces it is more efficient when it use electrodes with the active area with sharp form.

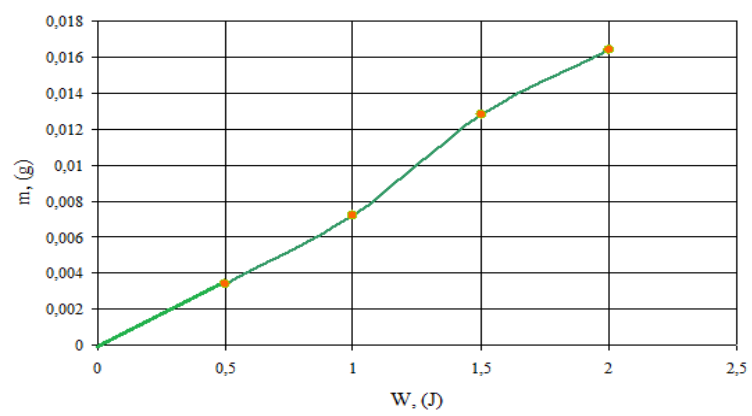

Fig. 2. The variation tool electrode wear of depending on the accumulated energy in the capacitor. The active zone of electrode tool has the shape sharp cone form 
From the analysis of bibliographic sources [7, 14-15] and further experimental research it was found that removal of the vaporized material is more pronounced from the surface of the cathode compared to the similar phenomenon that would occur on the anode. Effectiveness of obtaining of graphite films when the tool electrode is connected to the anode pole is very low, for which reason, the electrode erosion phenomenon have not been studied in detail.

For the manufacturing of electrode a material with high resistance to erosion is required, because the electrode wear of involves changings of the interstitial space (space between the electrode tool and the metal surface on that deposition is occurs). Modification of interstitial space leads to the changing for operating parameters of the submission procedure which leads to failures of the processing technology.

According to the previously results obtained, [11-13] erosion stability of the materials is determined by thermosetting properties thereof and it is explained by the relationship (1).

$$
\gamma=C \rho \lambda T_{n n}^{2}
$$

$C$ - thermal capacity;

$\rho$ - density;

$\lambda$ - thermal conductivity;

$T_{n n}^{2}$ - melting temperature.

The material which the electrode tool it is made is pyrolytic graphite. Electrode shape is obtained after a splintering processing operations. The final form of the electrode tool is a cylinder with a diameter of $6 \mathrm{~mm}$. If is necessary, the electrodes with smaller diameter up to $1 \mathrm{~mm}$ can be made. The shape of the active zone of the electrode tool is selected depending on the wanted processing parameters and is carried out following a splintering processing operations too.

When applying spots of graphite following pulsed electrical discharges on the metallic surface to be processed the necessary condition is that graphite spot to be applyed on a cold surface. The electrode shape that best satisfies this technological condition is cylindrical rod or disk.

Knowing the frequency of electrical impulses, the diameter of the interaction zone of electric discharge from the active surface area of the electrode tool the linear speed for submission can be determined with the mathematical relationship (2).

$$
V=f d
$$

$f$ - frequency of succession for working pulse;

$d$-diameter zone of interaction of plasma channel with the electrode surface.

The frequency of succession for working pulse is determined by pulse generator settings and $d$ diameter zone of interaction of plasma channel with the electrode surface is calculated using the relationship (3):

$$
d=\sqrt{\frac{4 W}{Q S}}
$$

or it is experimentally determined using the relationship (4).

$$
W=\int_{0}^{\tau} i(t) U(t) d t
$$

In the relationship (3): 
$\mathrm{W}$ - energy released in the interstitium;

$\mathrm{Q}$ - melting heat;

$\mathrm{S}-$ size of interstitium.

\subsection{Scanning electron microscopy analysis (SEM)}

The analysis of processed surface morphology under pulsed electrical discharges using pyrolytic graphite electrode tool it showed that physico-chemical changes were not exceed micrometer depth. Besides the main component of processed material - ie pyrolytic graphite the analyzes attest a significant amount of atomic carbon. This leads to the conclusion that on the processed surface is also formed binary compounds of carbon carbides which demonstrates the enhancement of the resistance for processed metallic surface to mechanical actions.
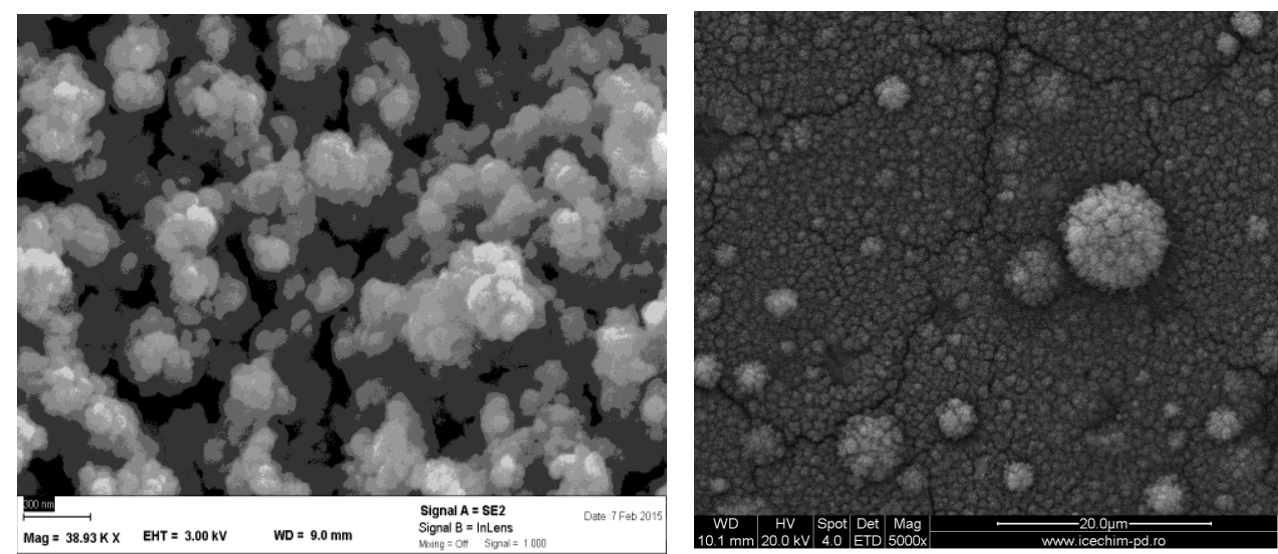

Fig.3. The morphology of graphite film deposited by pulsed electrical discharge on the surface of steel OL45

Analyzing the presented images that make up the Figure 3 it can be seen that the film of graphite contains a series of nanometric globular formations. This explains a number of interesting properties of graphite film which will be presented in Chapter thermogravimetric analysis.

Identification and method for obtaining of these spatial formations composed of carbon atoms by a procedure unspecified in scientific specialized literature is a novelty and represents the main scientific discovery of the $\mathrm{PhD}$ thesis sustained by the $\mathrm{PhD}$ student Marin Laurentiu.

\subsection{Thermogravimetric analysis (TGA)}

The presence of globular formations on the surface of graphite film identified by SEM imaging determined performing of additional analyzes.

A result of performing thermo-gravimetric analyzes of the graphite film deposited by pulsed electrical discharges process it has found a number of interesting addition of mass phenomena. [29].

They are reversible and occurred at the following values of the working temperature $222,99^{\circ} \mathrm{C} ; 476,12^{\circ} \mathrm{C}$ and $614,73^{\circ} \mathrm{C}$ (fig. 5).

These mass additons occurred in conditions which thermo-gravimetric analysis were held in nitrogen environment $\mathrm{N}_{2}$. This phenomenon is explained by the obtaining of spatial 
formation of carbon fullerenes and carbon nanotubes [17-25, 27, 29] type who have the ability to encapsulate small molecules $\left(\mathrm{N}_{2}\right)$ (fig.6a).

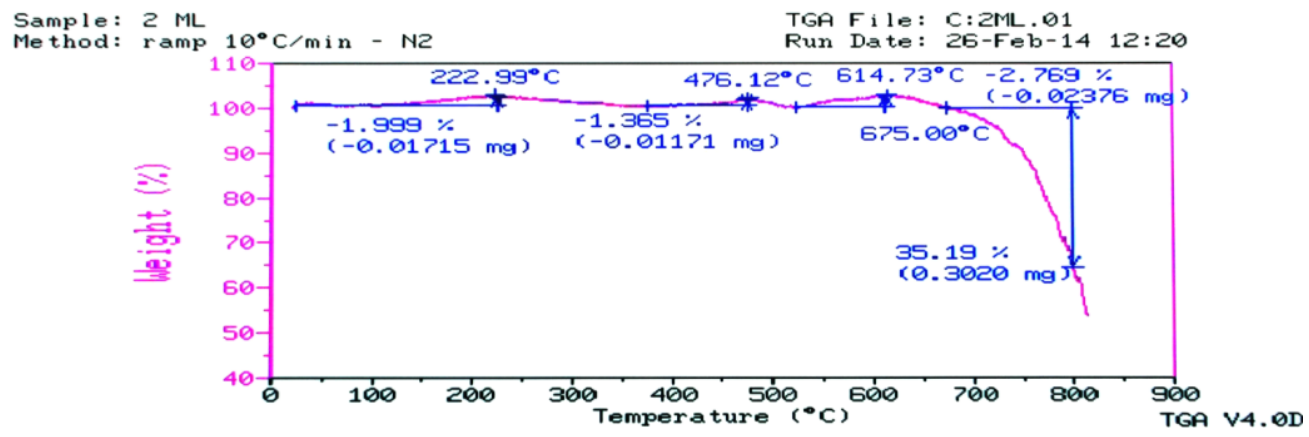

Fig.4. Thermogravimetric curve graphite of the film deposited by pulsed electrical discharges process

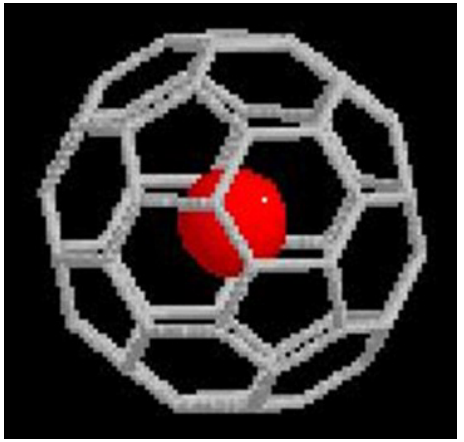

a)

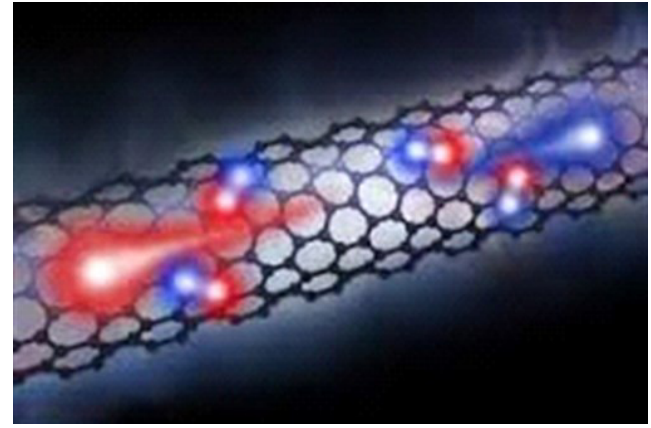

b)

Fig. 5. Graphic presentation of spatial structures of carbon: a)-fullerenes that encapsulates nitrogen molecules; b) - carbon nanotubes that encapsulate: $\mathrm{OH}^{-}, \mathrm{O}-\mathrm{C}$ and $\mathrm{O}-\mathrm{C}=\mathrm{O}$

Following this analysis we determined that the film of graphite also contains a number of other compounds containing in their molecule atoms of oxygen $\mathrm{OH}^{-}, \mathrm{O}-\mathrm{C}$ and $\mathrm{O}-\mathrm{C}=\mathrm{O}$. [30]. They are the result of oxidation processes that occur unavoidably during the graphite film submission considering that the process unfolds in normal atmosphere.

\section{Conclusion}

The submission of graphite films by electrical discharges in pulse in process is influenced by the geometry of the active part of the electrode tool.

Graphite films deposited by pulsed electrical discharges process have anticorrosive properties, following the submission of an inert airtight film on the surface of metal pieces, protecting them by aggressive actions of corrosive agents;

At the same time with graphite films deposited by pulsed electrical discharges process is also obtained a series of spatial formations composed of carbon atoms fullerenes and carbon nanotubes type which determine the mass addition phenomenon.

Identification and method for obtaining of these spatial formations composed of carbon atoms by a procedure unspecified in scientific specialized literature.

They represent the main scientific discovery of the $\mathrm{PhD}$ thesis sustained by the $\mathrm{PhD}$ student Marin Laurentiu. 


\section{References}

1. V.P. Luneva, A.D. Verhoturov, A.V. Coziri, T.V. Glabet, V.N. Brui. EPI, 4, 11-18 (2005)

2. F. H. Burumculov, P.P. Lezin, P.V. Senin, V.I. Ivanov. The electric discharge tehnology aimed at retreading and hardening of the machining pieces and tools. (USM "Ogareva", Saransk, 2003)

3. P. Topala. The transfer of mass and diffusion processes on surface layers of engine parts during electrosparkle processing. Saint-Petersburg, 2, 234-242 (2007)

4. V. Beshliu. Technologies in machine building, 1, 24-30 (2008)

5. A. Mihaliuc. EPI., 3, 21-23 (2003)

6. P. Topala. Nonconventional technologies review, 1, 129-132 (2007)

7. P. Topala, V. Beshliu. Bulletin of the Polytechnic Institute of Iasi, 54, 105-111 (2008)

8. P. Topala, P. Stoicev, A. Epureanu, V. Beshliu. International Scientific and Technical conference Machinebulding and technosphere of the XXI century, Donetk, 262-266 (2006)

9. P. Topala, P. Stoicev. Tehnologii de prelucrare a materialelor conductibile cu aplicarea descărcărilor electrice în impuls, (Chişinău, TEHNICA - INFO, 2008)

10. P. Topala, V. Beshliu, S. Petru, O. Alexandr. International Journal of Modern Manufacturing Technologies, 2, 97-102 (2013)

11. P. Topala, L. Marin, V. Beşliu. Advanced Manufacturing Technologies, 97-104 (2013)

12. Yu. V. Kurochkin, and Yu. N. Demin. Chemical and Petroleum Engineering, 37, 404-408 (2001)

13. A. Mihaliuc. EPI, 3, 21-23 (2003)

14. B. Ekmekci, O. Elkoca, A. Erden. ProQuet Science Journals, 36B, 117-124 (2005)

15. V. Beshliu. Technologies in machine bulding, 1, 75-82 (2008)

16. P. Topala, S. Mazuru, V. Beshliu, P. Cosovschii, A. Ojegov. ModTech, Vadul lui Voda-Chisinau, Republic of Moldova, 1093-1096 (2011)

17. G. Ruxanda, M. Stancu, S. Vizireanu, G. Dinescu, D. Ciuparu. Journal of Optoelectronics and Advanced Materials, 10, 8, 2047-2051 (2008)

18. J.B. Howard, J.T. McKinnon, Y. Makarovsky, A.L. Lafleur, M.E. Johnson. Nature 352 (6331), 139-141 (1991)

19. J. Howard, A. Lafleur, Y. Makarovsky, S.Mitra, C. Pope, T. Yadav. Fullerenes synthesis in combustion. Carbon 30 (8), 1183 (1992)

20. H.W. Kroto, J.R. Heath, S.C. O'Brien, R.F. Curl, R.E. Smalley, Nature 318 (6042), 162-163 (1985)

21. Y. Zhao, Y.-H. Kim, A.C. Dillon, M.J. Heben, S.B. Zhang. Physical Review Letters 94 (15), $155504(2005)$

22. A. Hirsch, C. Bellavia-Lund. Fullerenes and Related Structures (Topics in Current Chemistry). (Berlin, Springer, 1993)

23. F.N. Diederich. Pure and Applied Chemistry, 69 (3), 395-400 (1997)

24. Y. Li. Chemical Physics Letters 335 (5-6), 524 (2001)

25. P. Topala, S. Mazuru, V. Besliu, P. Cosovschii, A. Ojegov. Proceedings of The $15^{\text {th }}$ International Conference, Modern Technologies, Quality and Innovation. 2, 1093-1096 (2011)

26. P. Topala, V. Beshliu, L. Marin, Advanced Materials Research, 1036, 172-177 (2014)

27. P. Topala, V. Beshliu, A. Ojegov. Сборник трудов XVIII международной научно-технической конференции, Донеик, 240-245 (2011)

28. P. Topala; S. Mazuru; V. Besliu; P. Cosovschii; P. Stoicev. Proceedings of The $14^{\text {th }}$ International Conference, Modern Technologies, Quality and Innovation, 635-638 (2010)

29. J. M. Moon, K. H. An, Y. H. Lee, Y. S. Park, D. J. Bae, G. S. Park. Journal of Physical Chemistry B, 105 (24), 5677-5681 (2001)

30. I. Tiginyanu, P. Topala, V. Ursaki. Nanostructures and Thin Films for Multifunctional Applications, (Springer, 2016) 